\title{
Molecular diffusion in ternary poly(vinyl alcohol) solutions
}

\author{
Katarzyna Majerczak ${ }^{1}$, Ophelie Squillace ${ }^{1}$, Zhiwei Shi ${ }^{2}$, Zhanping Zhang ${ }^{2}$, Zhenyu J. Zhang (ه) ${ }^{1}$ \\ 1 School of Chemical Engineering, University of Birmingham, Birmingham B15 2TT, UK \\ 2 The Procter and Gamble Company, Cincinnati, $\mathrm{OH} 45040$, USA
}

(C) The Author(s) 2021. This article is published with open access at link.springer.com and journal.hep.com.cn

\begin{abstract}
The diffusion kinetics of a molecular probe - rhodamine B - in ternary aqueous solutions containing poly(vinyl alcohol), glycerol, and surfactants was investigated using fluorescence correlation spectroscopy and dynamic light scattering. We show that the diffusion characteristics of rhodamine B in such complex systems is determined by a synergistic effect of molecular crowding and intermolecular interactions between chemical species. The presence of glycerol has no noticeable impact on rhodamine $\mathrm{B}$ diffusion at low concentration, but significantly slows down the diffusion of rhodamine B above $3.9 \%(\mathrm{w} / \mathrm{v})$ due to a dominating steric inhibition effect. Furthermore, introducing surfactants (cationic/nonionic/ anionic) to the system results in a decreased diffusion coefficient of the molecular probe. In solutions containing nonionic surfactant, this can be explained by an increased crowding effect. For ternary poly(vinyl alcohol) solutions containing cationic or anionic surfactant, surfactantpolymer and surfactant-rhodamine B interactions alongside the crowding effect of the molecules slow down the overall diffusivity of rhodamine $\mathrm{B}$. The results advance our insight of molecular migration in a broad range of industrial complex formulations that incorporate multiple compounds, and highlight the importance of selecting the appropriate additives and surfactants in formulated products.
\end{abstract}

Keywords fluorescence correlation spectroscopy, poly (vinyl alcohol), anomalous diffusion, crowding effects, dynamic light scattering, binding effects, rhodamine B

\section{Introduction}

Poly(vinyl alcohol) (PVA) is widely used in consumer products due to its high degree of water solubility,

Received June 12, 2021; accepted September 18, 2021

E-mail: z.j.zhang@bham.ac.uk exceptional film forming capability [1,2], low toxicity [2], approved biodegradability [3,4], and excellent barrier properties [5]. As a packaging material [6-8], PVA is exposed to additives and surfactants through the life cycle of a formulated product. Migration of additive molecules in such complex matrices has a significant impact on the manufacturing process, as well as product shelf-life and performance, therefore is determined by the molecular interactions between PVA and the small molecules, often in an aqueous environment.

Building upon a well-established theoretical framework $[9,10]$, diffusion is commonly considered as the meansquare displacement of the moving entity, which changes proportionally with its diffusion time [11]. However, molecular diffusion in polymer solutions that contain multiple components [12,13] should be considered by more specific models, such as obstruction effect models $[14,15]$, free volume theory-based models $[16,17]$, and hydrodynamic models $[18,19]$. Despite the advancements, these mechanisms do not adequately describe diffusion in complex mixtures of polymers and surfactants [20,21], proving the need for further investigations. The size, shape, and flexibility of the molecules were proven to significantly influence the magnitude of the rotational dynamics [22] and translational diffusion coefficient [23-26] due to temporary confinement [25], molecular crowding [27], and reversible binding to 'traps' in the system [28]. Furthermore, intermolecular interactions between solutes and solvent are often complex, substantially influencing the anomalous character of diffusion in polymer solutions.

Investigations into the mechanisms that determine the molecular diffusion in PVA solutions are further complicated by the formation of complexes in the presence of charged molecules (e.g., surfactants) [29,30]. For example, surfactants were shown to influence the viscosity of PVA solutions because of the changes in intermolecular interactions [31,32] and formation of molecular aggregates [33].

For polymer solutions, extensive studies had been carried out to investigate the magnitude of the intermolecular interactions and the formation mechanisms of 
complexes [29,31,32,34-36], with less attention paid on the effect of the additives on the molecular diffusion characteristics. Furthermore, the majority considers only a binary system that contains the polymer and a particular guest molecule. To understand the molecular interactions in a complex, multi-component polymer solution that is relevant to industrial applications, four components are essential: solvent, polymer, plasticiser, and another additive (i.e., a surfactant of various head group chemistry).

Molecular diffusion in a polymer solution can be measured by a range of techniques, including fluorescence methods such as fluorescence correlation spectroscopy (FCS) [37], dynamic light scattering (DLS) [38,39], pulsedfield gradient spin-echo nuclear magnetic resonance [40], and centrifugation (sedimentation) [41,42]. They can be further divided into techniques measuring self-diffusion coefficient (describing the motion of the molecule due to the thermal motion that is relative to the surrounding molecules) and cooperative diffusion coefficient (transport of a number of molecules due to density gradient), both of which offer critical information about migration behavior of molecules in a controlled environment [43].

Among the techniques measuring self-diffusion coefficient, FCS enables investigation at the single-molecule level, with minimal disruption to the system being investigated. It has been used to characterize the selfdiffusion of both polymer [44-47] and probe of various sizes, chemistry and concentration in both dilute and semidilute solutions [12,48-53], revealing the binding [43], reaction kinetics [54], and crowding effects [55], and offering the capability to explore an unknown microstructure [56]. FCS also enables investigations into diffusion mechanisms [57], differentiating anomalous $[11,28,58,59]$, walking-confinement [60], and time-dependent diffusion behaviors [61]. DLS, on the other hand, is used widely to measure the cooperative diffusion coefficient, but is incapable of examining multicomponent systems as all solutes contribute to the scattering signal [12].

In the present study, we investigated the effects of crowding and intermolecular interactions on the molecular diffusion in ternary mixtures that replicate PVA based chemical products dissolved in water. Rhodamine B $(\mathrm{RhB})$, a well-characterized [62], industrially applied fluorophore [63-65] was selected. Initially, diffusion of $\mathrm{RhB}$ in PVA solutions of different polymer concentrations was measured by FCS, and analyzed by a hydrodynamic stretched exponential model, to examine the effects of molecular crowding [66]. Glycerol, a plasticiser commonly used for PVA formulations [67], was subsequently introduced to observe its effect on the diffusion of RhB. Finally, surfactants of various head groups (cationic/ nonionic/anionic) were introduced to investigate the effect of detergent on molecular diffusion. By introducing complexity in a stepwise fashion, the contribution of each newly added component was examined independently. The specific interactions between each component could be characterized, revealing three primary effects: the behavior of the polymer itself, the overall molecular crowding in the system, and specific (charged) interactions between individual species, which could enable a prediction of molecular behavior in complex systems.

\section{Experimental}

\subsection{Materials}

PVA (Sigma-Aldrich P8136, molecular weight $\left(M_{\mathrm{w}}\right)=30$ $70 \mathrm{~kg} \cdot \mathrm{mol}^{-1}$, degree of hydrolysis $\left.(\mathrm{DH})=87 \%-90 \%\right)$, glycerol (Sigma-Aldrich G9012, $\geqslant 99.5 \%$ ), sodium dodecyl sulfate (SDS, Fisher Scientific S/5200/53), decaethylene glycol monododecyl ether $\left(\mathrm{C}_{12} \mathrm{E}_{10}\right.$, Sigma-Aldrich P9769), cetyltrimethylammonium bromide (CTAB, Sigma-Aldrich $\mathrm{H} 5882, \geqslant 98 \%$ ), RhB (Sigma-Aldrich R6626, $\geqslant 95 \%$, HPLC), and HPLC water (HPLC Plus, Sigma Aldrich 34877-M) were purchased and used as received. Chemical structures of the components used in this study are shown in Fig. 1.

\subsection{Sample preparation}

PVA stock solution $(4 \%(\mathrm{w} / \mathrm{v}))$ was prepared by adding pure PVA to HPLC water and heating up to $75^{\circ} \mathrm{C}$ with

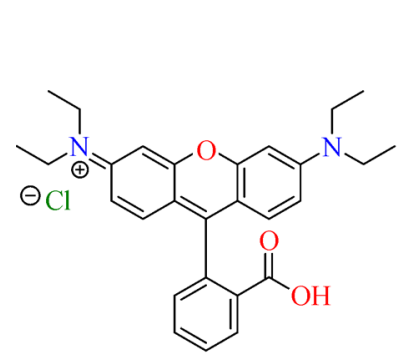

$\mathrm{RhB}$

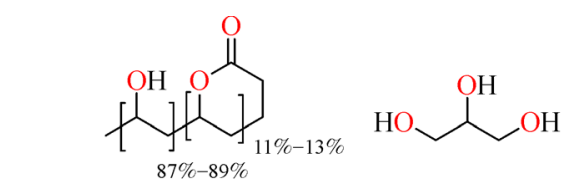

PVA Glycerol

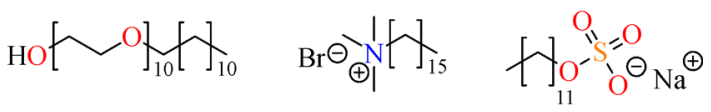

$\begin{array}{ccc}\mathrm{C}_{12} \mathrm{E}_{10} & \mathrm{CTAB} & \text { SDS }\end{array}$

Fig. 1 Chemical structures of the compounds used. 


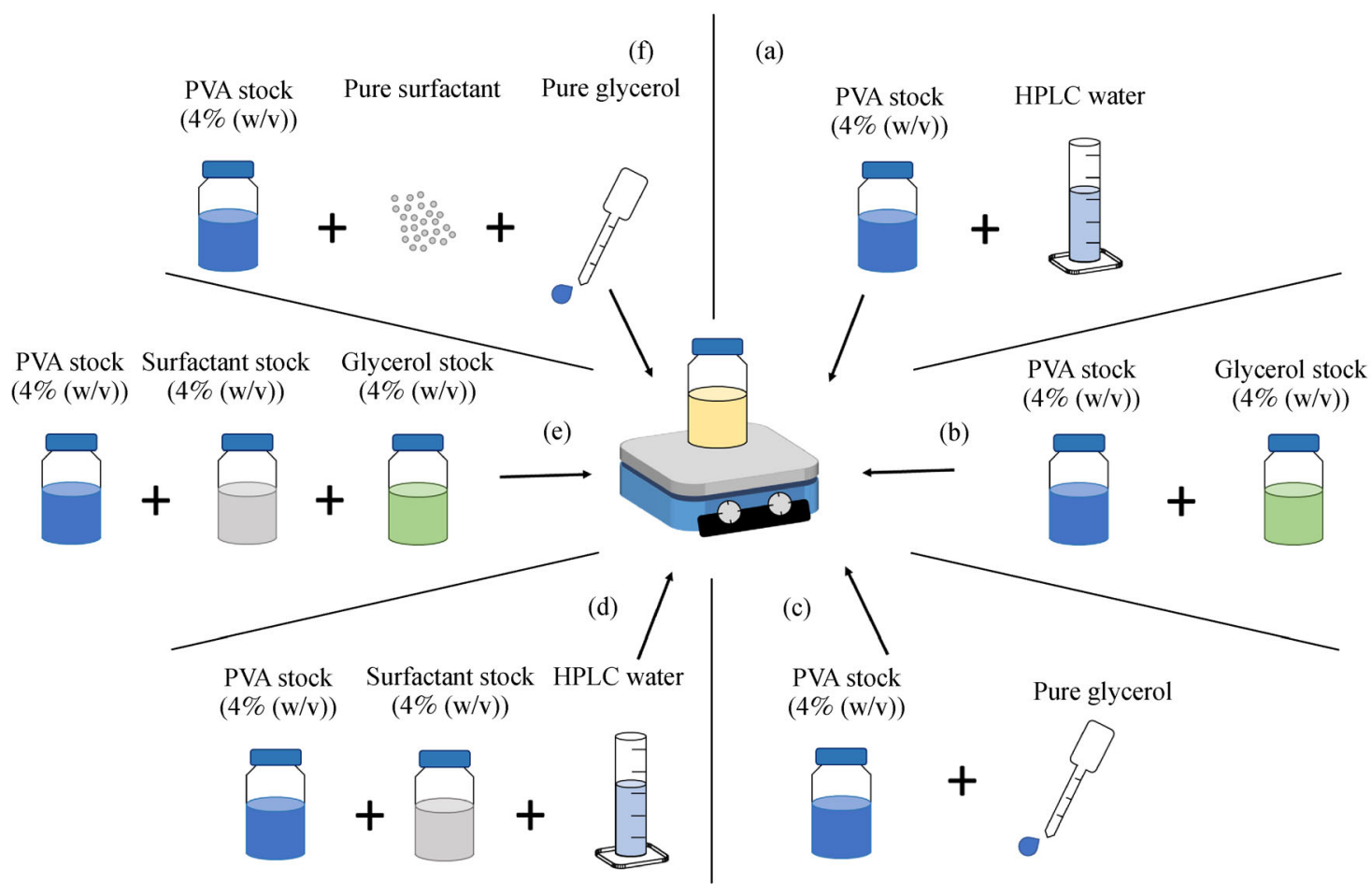

\begin{abstract}
Scheme 1 Preparation method for test solutions of various compositions: (a) PVA solutions of various concentrations, (b) PVA/glycerol solutions of various ratio of components (with changes in PVA concentration), (c) PVA/glycerol solutions of various ratio of components (with almost constant PVA concentration), (d) PVA/surfactant solutions, (e) PVA/glycerol/surfactant solutions, and (f) concentrated PVA/ glycerol/surfactant solutions.
\end{abstract}

continuous stirring for ca. $2 \mathrm{~h}$. Solutions of glycerol, anionic surfactant (SDS), and cationic surfactant (CTAB) were prepared by dissolving required amount of substance and stirring at room temperature for ca. $4 \mathrm{~h}$ to prepare solutions of $4 \%(\mathrm{w} / \mathrm{v}), 1 \%(\mathrm{w} / \mathrm{v})$, and $1 \%(\mathrm{w} / \mathrm{v})$, respectively. When SDS or CTAB solutions were visibly cloudy, they were heated up to $50{ }^{\circ} \mathrm{C}$ for $15 \mathrm{~min}$ to remove surfactant mesophases [68]. Stock solutions of $1 \%(\mathrm{w} / \mathrm{v})$ nonionic surfactant $\left(\mathrm{C}_{12} \mathrm{E}_{10}\right)$ were prepared by dissolving the compound at $30^{\circ} \mathrm{C}$ with continuous mixing for ca. $2 \mathrm{~h}$ and stirring at room temperature. All stock solutions prepared were below their solubility limits.

Multiple sets of solutions were prepared by mixing PVA/ glycerol/surfactant stock solutions at various volumetric ratios, as presented in Scheme 1, to examine: 1) Effect of PVA concentration in the absence of other additives (Scheme 1(a)); 2) effect of glycerol addition at various concentrations (Schemes 1(b) and 1(c)); 3) effect of surfactant in the absence of glycerol (Scheme 1(d)); 4) synergistic effect of both surfactant and glycerol at a 12:4:1 PVA/glycerol/surfactant mass ratio (Schemes 1(e) and 1 (f)). Molecular probe, RhB was introduced to the corresponding test solutions using a $2.5 \mathrm{mmol} \cdot \mathrm{L}^{-1}$ stock solution to obtain a final concentration of $50 \mathrm{nmol} \cdot \mathrm{L}^{-1}$. A piranha solution cleaned coverslip [69] with $50 \mu \mathrm{L}$ of each as prepared solution was used for FCS analysis.

\subsection{Fluorescence correlation spectroscopy}

FCS measurements were performed on a ZEISS LSM 710 confocal microscope under a $40 \times$ water immersion objective. RhB was excited using the $488 \mathrm{~nm}$ line of the $\mathrm{Ar}$ laser at $5 \%$ of its maximum power, with the $505-610 \mathrm{~nm}$ band-pass filter used to collect the fluorescence emission.

Diffusion coefficient of the RhB in water is well documented in the literature $\left(3.6 \times 10^{-10} \mathrm{~m}^{2} \cdot \mathrm{s}^{-1}\right.$ at $21.5^{\circ} \mathrm{C}$ ) [37], which was used to calibrate the width of the confocal volume, using Einstein's equation [37]:

$$
D=\frac{w_{x y}^{2}}{4 \tau_{\mathrm{D}}}
$$

where $w_{x y}$ is the width of the confocal volume, $\tau_{\mathrm{D}}$ is the average diffusion time of $\mathrm{RhB}$ through the confocal volume, and $D$ is the diffusion coefficient of $\mathrm{RhB}$ in given solution. Equation (2) was used to correct the effect of temperature on the diffusion coefficient of $\mathrm{RhB}$ :

$$
D_{\mathrm{RhB}}=\frac{D_{21.5} T_{x} \eta_{21.5}}{T \eta_{x}},
$$

where $D_{\mathrm{RhB}}$ and $D_{21.5}$ are diffusion coefficients of $\mathrm{RhB}$ in water at the temperature of experiment $\left(T_{x}\right)$ and $21.5{ }^{\circ} \mathrm{C}$ $\left(T_{21.5}\right)$, respectively, while $\eta_{x}$ and $\eta_{21.5}$ represent the 
corresponding solution viscosity. Using the ZEN 2010 software, the autocorrelation data acquired was analyzed using the free diffusion model that takes into account the possibility of triplet state during measurement, with diffusion coefficient of $\mathrm{RhB}$ in given solution calculated using Eq. (1).

\subsection{Rheology}

A HR-1 Discovery Hybrid Rheometer with double wall geometry was used to quantify the viscosity of the PVA solutions (without $\mathrm{RhB})$ at a constant temperature $\left(25^{\circ} \mathrm{C}\right)$ as a function of shear rate. Prior to each measurement, solutions were sonicated for $20 \mathrm{~min}$ at ca. $25^{\circ} \mathrm{C}$, and then allowed to cool to ambient temperature. The rheological data were fit to the Herschel-Bulkley model [70] by the TRIOS software to estimate the viscosity at zero shear rate.

\subsection{Dynamic light scattering}

DLS measurements were performed using a Zetasizer (Nano-ZS, Malvern Instruments, UK) with a measurement angle of $178^{\circ}$ and beam wavelength $632.8 \mathrm{~nm}$ at $25^{\circ} \mathrm{C}$. Due to the presence of multiple species in some of the sample solutions, hydrodynamic diameter $\left(d_{\mathrm{H}}\right)$ distribution was measured as a function of intensity [71] over three repeats. Hydrodynamic diameter was estimated using the Malvern software.

\section{Results and discussion}

3.1 Determining the appropriate model for PVA diffusion in solution

Dynamics of polymers in solution is determined by their concentration, with three distinguishable regimes: in the dilute regime, each polymer chain can be treated individually; in the intermediate semi-dilute regime, polymer coils overlap and their diffusion is dominated by a reptation process, with chains moving primarily parallel to their own backbones; while in the concentrated regime, chains are in close proximity to the others, with consequent interactions $[45,72]$. A polymer solution is in the semidilute regime when its concentration is greater than the overlap concentration $\left(c^{*}\right)$ that can be calculated according to Eq. (3) [45]:

$$
c^{*}=\frac{3 M_{\mathrm{w}}}{4 \pi N_{\mathrm{A}} R_{\mathrm{g}}^{3}},
$$

where $N_{\mathrm{A}}$ is Avogadro's number, and $R_{\mathrm{g}}$ is the radius of gyration. $R_{\mathrm{g}}$ of the PVA molecules used in the present work is in the region of $6.7-10.3 \mathrm{~nm}$, calculated with Eq. (4) [73]:

$$
R_{\mathrm{g}}=0.0388 M_{\mathrm{w}}^{0.5} .
$$

Minimum value of $c^{*}(1.1 \mathrm{wt} \%)$ suggests that most of the investigated solutions in the present work are in the semi-dilute regime, wherein the thermodynamic behavior is governed by a specific correlation length $(\xi)$ - the average distance between the points of entanglement of different chains.

The difference between $\xi$ and the size of the molecular probe introduces three sub-regimes of semi-dilute regime: for probes whose size is either far greater or smaller than $\xi$, viscosity of the solution or pure solvent, respectively, determine their diffusion rates [12,58]. However, for molecular size that is of the same order of magnitude as $\xi$ (ca. $1.14 \mathrm{~nm}$ for $\mathrm{RhB}$ ) [75], further investigation into dominating factors controlling the diffusion processes is required [12]. To assess $\xi$, Eq. (5) was used [75]:

$$
\frac{R_{\mathrm{g}}}{\xi}=\left(\frac{c}{c^{*}}\right)^{0.75}
$$

where $c$ is concentration of polymer solution. The average values of $\xi$ (Table 1) and its minimum in the currently investigated system $(2.6 \mathrm{~nm})$ are either lower or of the same magnitude as $R_{\mathrm{g}}$ of PVA, confirming the finding that all samples investigated can be treated as belonging to semi-dilute regime [76]. Moreover, since the value of $\xi$ is in general of the same order of magnitude as $d_{\mathrm{H}}$ of the tracer used, it is appropriate to use the third subregime. Therein, a semi-empirical stretched exponential function (such as in Eq. (6)) [66] has been developed to describe its diffusion behavior:

$$
\frac{D}{D_{0}}=\exp \left(-\beta c^{n}\right)
$$

where $D_{0}$ is the diffusion coefficient of $\mathrm{RhB}$ in pure solvent; $n$ is a scaling parameter related to the polymer chain excluded volume, which reflects the solubility of the polymer ( $n=1$ for theta solvent and $n=0.75$ for good solvent); and $\beta$ is a pre-factor related to the probe size that can be described by Eq. (7) [12]:

$$
\beta=\frac{R}{r \cdot c^{* n}},
$$

where $R$ is the radius of the probe, and $r$ is the average polymer chain size, signifying that $\beta$ scales linearly with the size of the probe particle, which was confirmed experimentally [12]. Equation (6) provided a satisfactory fit for changes of diffusion coefficient of particles in semidilute PVA solutions [12], and was used in the present work to interpret diffusivity measurements as a function of PVA concentration with or without the addition of glycerol to estimate $\beta$ and $n$.

\subsection{Molecular diffusion in PVA solutions}

Diffusion of the molecular probe, $\mathrm{RhB}$, in PVA solutions was quantified using FCS with three sets of independent 
experiments on different days. Figure 2 shows the relationship between the measured diffusion coefficients $(D)$, upon satisfactory fit of the autocorrelation function (Fig. S1, cf. Electronic Supplementary Material, ESM), and the concentrations of PVA (0-4\% (w/v)), using Eq. (6). It was found that there is a decrease in $\mathrm{RhB}$ diffusion coefficient (from $432.4 \mu \mathrm{m}^{2} \cdot \mathrm{s}^{-1}$ to $188.4 \mu \mathrm{m}^{2} \cdot \mathrm{s}^{-1}$ for solutions 1 and 6 , respectively) with an increased PVA concentration. Using the least squares method, values of $\beta$ $=0.270 \pm 0.019$ and $n=0.767 \pm 0.046$ were obtained, which are consistent with the values reported in literature for tracer molecules of similar chemistry and/or size [12], and confirming that water is a good solvent for PVA $(n \approx$ 0.75 ).

The observed reduction in the diffusivity of $\mathrm{RhB}$ is likely attributed to the increased crowding density (itself a function of the polymer concentration), which can be directly correlated with the reduced hydrodynamic diameter of PVA $\left(d_{\mathrm{H}}\right)$ determined by DLS (Fig. 3(a)) and the corresponding $\xi$ (Table 1). For all of the investigated solutions, a polymodal size distribution was observed, which is inconsistent with a previous report for PVA of similar DH [77], but agrees with the behavior of an almost completely hydrolysed PVA [78]. According to the calculated $R_{\mathrm{g}}$, peak I in Fig. 3 is assigned to the individual PVA chains, of which the maximum is shifted to lower $d_{\mathrm{H}}$ when there is less room available as the result of an increased number of molecules. This in turn leads to a significantly increased crowding density, impeding the migration of the probe. It is likely that peak II found in the size distribution profiles in Fig. 3 corresponds to polymer aggregates [78], while peak III is a sign of large clusters [79] in the solution. Considering that the scattered light intensity is proportional to diameter of given particle to the sixth power, the signal scattered from aggregates in intensity plot is amplified [80]. Majority of the scattered signal detected contributes to peak I, suggesting that the quantity of polymer aggregates and clusters is rather insignificant in the present work.

Hydrodynamic radius of PVA was estimated to be in the range of 10.3-15.9 nm, following Eq. (8) [81]:

$$
\frac{d_{\mathrm{H}}}{R_{\mathrm{g}}}=1.5 \text {. }
$$

The value calculated from Eq. (8) is greater than the average $d_{\mathrm{H}}$ acquired from samples 2-6 (Table 1), which is likely due to the presence of steric obstructions in discussed system. Since water is a good solvent for PVA, only weak excluded-volume interactions are present, with changes in viscosity directly correlated with the overlapping of the polymer chains [82]. The increased solution viscosity with increasing polymer concentration (Table 1) alongside the crowding density effects proven by DLS measurements confirms the effect of polymer-polymer interactions on molecular migration in the semi-dilute regime.

\subsection{Molecular diffusion in PVA/glycerol binary solutions}

Glycerol, commonly used as a plasticiser for PVA based products such as water soluble films [83], competes with PVA molecules to form PVA-glycerol hydrogen bonds at the expense of PVA-PVA hydrogen bonds. However, both types of interaction could be hampered when glycerol and PVA molecules are well solvated by an excessive amount of water. Addition of glycerol led to an increased viscosity (Table 2), reducing the diffusivity of the molecular probe due to the additional crowding effects.

To distinguish the effects of the overall solute concentration and the interactions between PVA and glycerol, two additional sets of samples ( $1 \mathrm{a}-5 \mathrm{a}$ and $2 \mathrm{~b}-$ $5 \mathrm{~b})$ were prepared, keeping either the total (PVA + glycerol) or PVA concentration constant, for which the molar ratio between PVA and glycerol was equivalent (i.e., the PVA/glycerol molar ratio in sample $2 \mathrm{a}$ is the same as in sample 2b). Compositions of the binary PVA/glycerol solutions investigated are presented in Table 2. As new species are introduced, it is expected that the $D$ of $\mathrm{RhB}$ will decrease, either due to PVA-glycerol interactions (leading to increased polymer-plasticiser aggregate size and consequent increase in $\mathrm{RhB}$ mean free path) or overall molecular crowding (leading to macroscale increase in viscosity).

\subsubsection{Synergistic effect of water and glycerol}

The diffusion coefficients of RhB in PVA/glycerol binary mixtures were found to decrease nonlinearly with an

Table 1 Compositions used to investigate the dependence of RhB diffusion coefficient on PVA concentration ${ }^{\text {a) }}$

\begin{tabular}{lcccc}
\hline Sample & PVA concentration $/ \mathrm{wt} \%$ & Average $\xi / \mathrm{nm}$ & Average $\eta /(\mathrm{mPa} \cdot \mathrm{s})$ & Average $d_{\mathrm{H}} / \mathrm{nm}$ \\
\hline 1 & 0.0 & 0.0 & $0.890[74]$ & - \\
2 & 1.0 & 19.9 & $1.184 \pm 0.016$ & $12.6 \pm 0.2$ \\
3 & 2.0 & 11.9 & $1.813 \pm 0.032$ & $8.2 \pm 0.1$ \\
4 & 3.0 & 8.8 & $2.669 \pm 0.024$ & $6.1 \pm 0.1$ \\
5 & 3.3 & 8.0 & $2.975 \pm 0.024$ & $6.0 \pm 0.1$ \\
6 & 4.0 & 7.1 & $4.052 \pm 0.081$ & $3.8 \pm 0.1$ \\
\hline
\end{tabular}

a) Average number of repeating units in PVA molecule used in the calculation is 581 . 


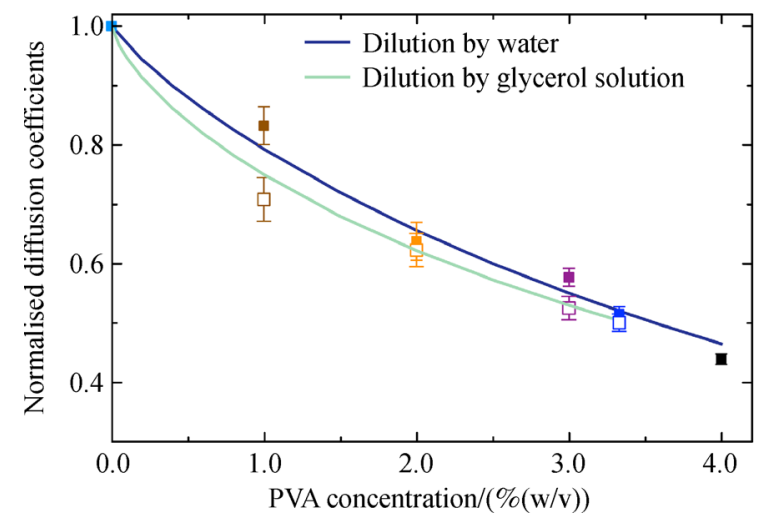

Fig. 2 Normalized diffusion coefficient of $\mathrm{RhB}$ as a function of PVA concentration without (samples 2-6) and with glycerol (samples 1a-5a). Solid lines represent fitting based on Eq. (6), with diffusion coefficient calculated using Eq. (1). Closed symbols correspond to PVA solution diluted with water, while open symbols are for PVA solution diluted with glycerol solution. Color code for each PVA concentration corresponds to DLS data (Fig. 3). Standard errors are based on 10 measurements.

increasing PVA concentration (Fig. 2), in a similar trend to that observed for PVA solution without glycerol (samples $2-5$ ). Both sets of FCS experiments (solutions with or without glycerol) were investigated on the same day to minimise the experimental errors due to any potential variations in environmental conditions, laser output, or calibration.

Overall, addition of glycerol solution instead of water led to an increased diffusion time for solutions of the same PVA concentration. Following a stretched exponential fit (Eq. (6)), $\beta$ and $n$ were estimated as $0.304 \pm 0.016$ and $0.666 \pm 0.036$ for samples $2 \mathrm{a}-5 \mathrm{a}$, accordingly. In here, glycerol stock solution was treated as a new solvent, hence diffusion coefficient of $\mathrm{RhB}$ in this solution was used as $D_{0}$ (Eq. (6)). Different fitted values both of $\beta$ and $n$ may arise due to the composition of the solvent, i.e., normalization against $D_{0}$. Statistical $t$-test result $(\alpha=0.05)$ confirms that there was no significant difference in the measured diffusion coefficients of RhB in PVA solutions with $(2 \mathrm{a}-$ $5 a)$ or without glycerol (2-5), as presented in Table S1 (cf. ESM). It can be concluded that concentration of PVA in the solvent plays a dominant role in determining the diffusivity of PVA at low glycerol concentration (up to $4 \%(\mathrm{w} / \mathrm{v})$ ).

The decreased value of $n$ indicates a reduced solvent quality, while the increased pre-factor $\beta$ suggests migration of molecule of larger size. These are attributed to the interactions between glycerol and the other species present. $\mathrm{RhB}$-glycerol interactions will slow the tracer diffusion directly due to entrainment of larger molecules in the solvation shell, whereas in the case of PVA, larger glycerol-PVA aggregates will increase the solution molecular crowding hence indirectly slowing tracer diffusion.

The latter is responsible for the changes observed in
PVA size distribution with samples 2a-5a (Fig. 3(b)). Similar to samples $2-5$, shift of the size distribution toward larger $d_{\mathrm{H}}$ with increasing dilution of the system is observed. However, increased viscosity and higher number of solute molecules present in samples $2 \mathrm{a}-5 \mathrm{a}$, in comparison to samples $2-5$, lead to the decrease in $d_{\mathrm{H}}$ of the PVA molecules (Tables 1,2), resulting in a decreased diffusion coefficient of the probe. Upon dilution by either pure water or glycerol solution, changes in the average $d_{\mathrm{H}}$ of PVA show an almost linear dependence on the viscosity of the solution, while the corresponding DLS autocorrelation functions show almost no change in its characteristics (Fig. S2, cf. ESM).

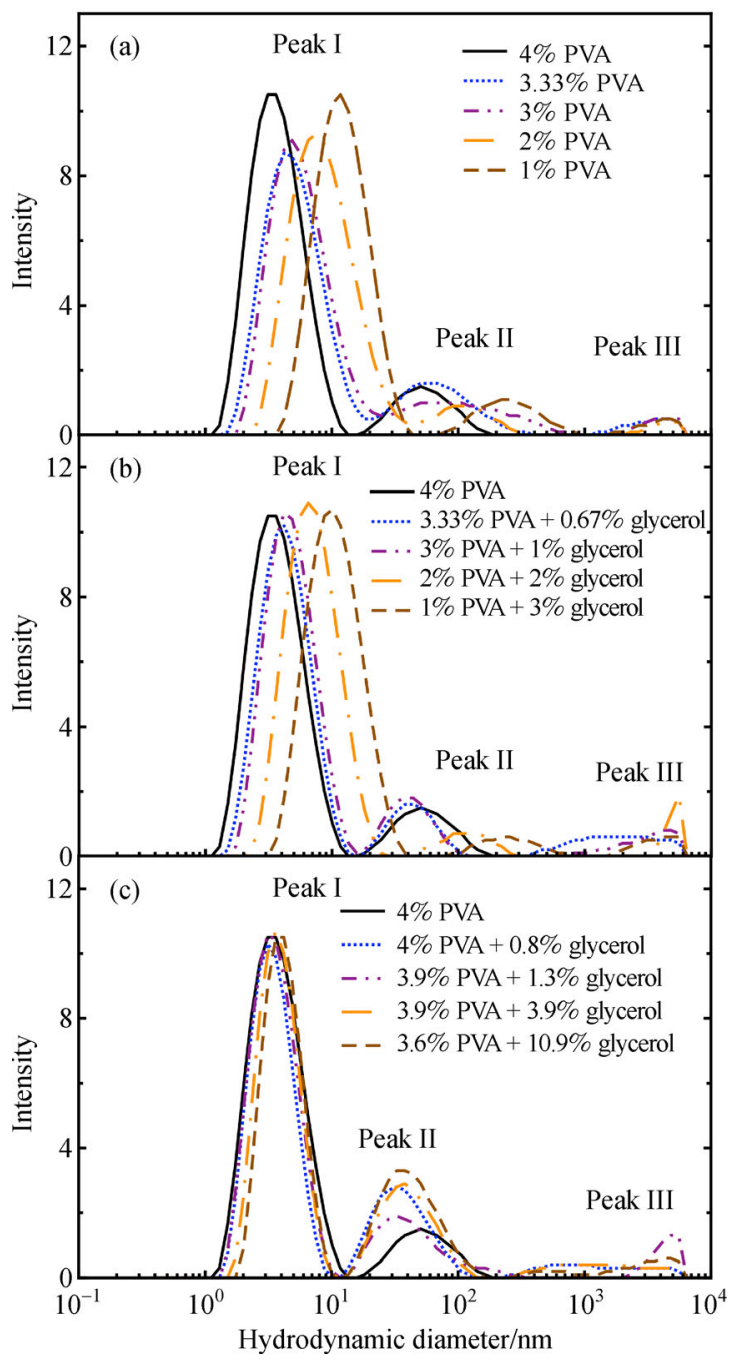

Fig. 3 Distribution of hydrodynamic diameter for solutions of various PVA concentration with the addition of (a) water, (b) glycerol stock solution, and (c) pure glycerol. The percentage of polymer in the graph is given in $\%(\mathrm{w} / \mathrm{v})$.

Although it is not possible to exclude the likelihood that the solvation shells of RhB molecules are expanded in glycerol solution, the DLS results acquired strongly imply 
that the additional crowding effects are responsible for the increased $\beta$ values. PVA concentration, however, showed a dominating influence. To clarify conclusions about observed mechanisms, further experiments using higher concentrations of glycerol were carried out.

\subsubsection{Effect of glycerol addition}

A set of PVA/glycerol binary mixtures (samples $2 \mathrm{~b}-5 \mathrm{~b}$, Table 2) were prepared by introducing pure glycerol to PVA solutions to distinguish the effects of glycerol and water on $\mathrm{RhB}$ diffusivity. The average diffusion coefficients (Fig. 4) show that glycerol has no notable impact on the $\mathrm{RhB}$ diffusion coefficient at low concentrations $(0 \%-$ $3.9 \%(\mathrm{w} / \mathrm{v}))$, but causes it to decrease at high concentrations $(>3.9 \%(\mathrm{w} / \mathrm{v}))$.

DLS results of this set of samples (Fig. 3(c)) indicate that increasing glycerol concentration causes a barely noticeable increase in $d_{\mathrm{H}}$ (the minimal shift of peak I that corresponds to the individual PVA molecules), as well an increased intensity of peak II. This suggests a formation of glycerol-PVA complexes (leading to the slight increase in $d_{\mathrm{H}}$ of peak I) and a greater number of polymer-polymer clusters (peak II). In contrast, for samples $2 \mathrm{a}-5 \mathrm{a}$ where the solute concentration was constant, the trend with increasing PVA concentration is similar to that of samples 2-5 (containing only PVA). It appears that chains become more compact (accelerated by the presence of other solutes) as PVA concentration increases to $4 \%(\mathrm{w} / \mathrm{v})$. Conversely, when PVA concentration is constant but overall solute concentration increases, glycerol-PVA complexes form, leading to the slight increase in measured $d_{\mathrm{H}}$.

Another factor that determines molecular diffusion is the solution viscosity, of which a constant value was observed up to 1:1 polymer to glycerol mass ratio (Table 2). Glycerol is therefore likely to disrupt polymer-polymer entanglements, which results in no viscosity changes. For sample $2 \mathrm{~b}$ (containing 10.9 wt\% glycerol), however, an increased solution viscosity was observed. It might be attributed to the high viscosity of glycerol itself (ca. $0.945 \mathrm{~Pa} \cdot \mathrm{s}$ for pure glycerol [84] $\mathrm{cf}$. $0.890 \mathrm{mPa} \cdot \mathrm{s}$ for water [74] at $25^{\circ} \mathrm{C}$ ), which becomes important once 1:1 ratio of components is reached.

It is worth noting that the increased glycerol content in samples $2 b$ and $3 b$ resulted in a broad range of diffusion times and consequent diffusion coefficient (as can be seen by relatively large error bars in Fig. 4 as glycerol concentration increases), with measurements of much slower diffusion time compared to samples $4 \mathrm{~b}$ and $5 \mathrm{~b}$ noted, and an overall decrease of $\mathrm{RhB}$ diffusivity. It is probable that samples $4 \mathrm{~b}$ and $5 \mathrm{~b}$ have a more homogeneous composition, where crowding effects is less important than for samples $2 b$ and $3 b$. Samples of low glycerol content show smaller changes in $d_{\mathrm{H}}$ (Table 2) compared against solution 6 (4.0 wt\% PVA only), which, together with the described viscosity behavior, leads to a similar diffusion coefficient of the tracer to that in PVA stock solution. As for sample $3 \mathrm{~b}$, increased amount of solute molecules is likely the more pronounced effect than viscosity values similar to that of PVA stock solution, despite the minor increase in the average $d_{\mathrm{H}}$. PVA-glycerol clusters therefore influence the migration of the molecular probe: the higher glycerol concentration, the more visible change in tracer's diffusion coefficient.

Generally, adding glycerol to PVA solutions at low concentrations without adjusting the overall water concentration has a minimal effect on the diffusion characteristics of $\mathrm{RhB}$ or the aggregation behavior of PVA compared to the results acquired in pure water. Addition of large quantity of pure glycerol, however, caused a reduction in the diffusivity of $\mathrm{RhB}$. It is worth noting that the size of PVA was very similar in these solutions, indicating that the hydrodynamic diameter of PVA is primarily dependent on its concentration, while the addition of glycerol appeared to promote the formation of PVA-glycerol complex. With this characterization of the effects of adding glycerol on the solution behavior, understanding the effect of introducing our model additives to the discussed system is now possible.

Table 2 Composition of PVA-based solutions with the addition of glycerol a)

\begin{tabular}{|c|c|c|c|c|c|c|}
\hline Sample & & $\begin{array}{l}\text { PVA concentration } \\
/ \mathrm{wt} \%\end{array}$ & $\begin{array}{c}\text { Glycerol concentration } \\
/ \mathrm{wt} \%\end{array}$ & $\begin{array}{l}\text { PVA/glycerol } \\
\text { molar ratio }\end{array}$ & $\begin{array}{l}\text { Average } \eta \\
/(\mathrm{mPa} \cdot \mathrm{s})\end{array}$ & $\begin{array}{l}\text { Average } d_{\mathrm{H}} \\
/ \mathrm{nm}\end{array}$ \\
\hline \multirow[t]{5}{*}{ Addition of glycerol solution } & $1 \mathrm{a}$ & 0.0 & 4.0 & $0: 1$ & $0.971 \pm 0.011$ & - \\
\hline & $2 \mathrm{a}$ & 1.0 & 3.0 & $1: 1629$ & $1.437 \pm 0.051$ & $10.4 \pm 0.1$ \\
\hline & $3 a$ & 2.0 & 2.0 & $1: 543$ & $2.136 \pm 0.026$ & $7.5 \pm 0.1$ \\
\hline & $4 a$ & 3.0 & 1.0 & $1: 181$ & $3.065 \pm 0.060$ & $5.2 \pm 0.1$ \\
\hline & $5 \mathrm{a}$ & 3.3 & 0.7 & $1: 109$ & $3.383 \pm 0.004$ & $4.7 \pm 0.1$ \\
\hline \multirow[t]{4}{*}{ Addition of pure glycerol } & $2 b$ & 3.6 & 10.9 & $1: 1629$ & $4.574 \pm 0.020$ & $5.2 \pm 0.2$ \\
\hline & $3 b$ & 3.9 & 3.9 & $1: 543$ & $4.020 \pm 0.044$ & $4.9 \pm 0.1$ \\
\hline & $4 \mathrm{~b}$ & 4.0 & 1.3 & $1: 181$ & $4.009 \pm 0.049$ & $4.4 \pm 0.1$ \\
\hline & $5 b$ & 4.0 & 0.8 & $1: 109$ & $4.024 \pm 0.097$ & $4.4 \pm 0.1$ \\
\hline
\end{tabular}

a) Samples of composition 1a did not provide reliable $d_{\mathrm{H}}$ results. 


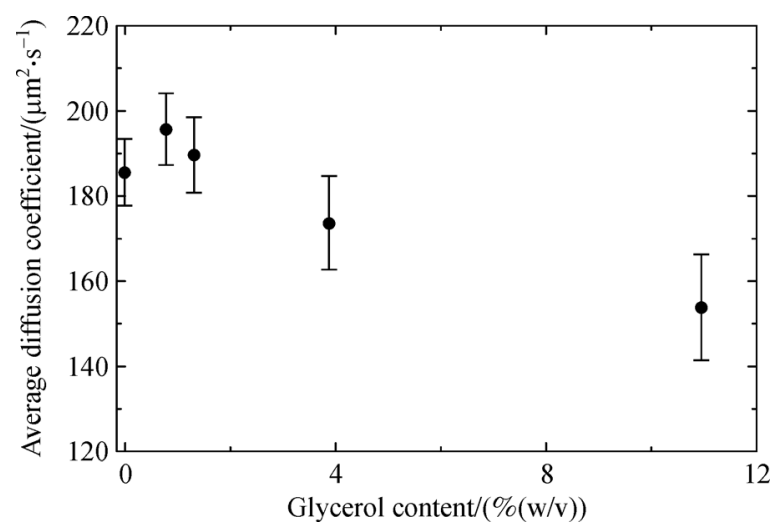

Fig. 4 Diffusion coefficient of RhB in PVA solution with the addition of pure glycerol. Error bars are one standard error around the mean, number of measurements equal to 10 .

3.4 Molecular diffusion in PVA/glycerol/surfactant ternary solutions

Diffusion of RhB in ternary aqueous solutions of PVA, glycerol, and surfactant, were studied to quantitatively establish the effects of crowding and binding on the mobility of the probe, as a function of the surfactant chemistry (cationic/nonionic/anionic). Specifically, the samples were prepared from polymer-surfactant mixtures (samples 4c-4e, Table 3), glycerol and surfactant solutions added to PVA solution (samples 4c-4h, Table 3 ), as well as from polymer solutions with the addition of pure glycerol and surfactant (samples $4 \mathrm{i}-4 \mathrm{k}$, Table 3 ). Instead of the effect of an increased molecular crowding, it is expected that strong directional (i.e., charge-matching) interactions between the ionic surfactants and the tracer will lead to the reduced diffusivity in the system. The nonionic surfactant, however, is expected to act similarly to glycerol.

\subsubsection{Addition of glycerol and/or surfactant stock solutions}

Average diffusion coefficients of RhB in PVA/glycerol/ surfactants ternary mixtures are presented in Fig. 5. It appears that the addition of surfactant led to a decreased diffusion coefficient of RhB: SDS has the most significant reduction (by 86\%), followed by CTAB (by 70\%), while $\mathrm{C}_{12} \mathrm{E}_{10}$ shows the least impact (by $31 \%$ ), compared with the control solution that had no surfactants. Surfactant seemed to change the nature of the molecular interactions via the formation of charge-matching complexes with RhB. Although this behavior would likely cause the ternary mixtures to become less homogeneous $[73,83]$, diffusion coefficients measured here show a monomodal distribution with low standard error, confirming that the average values reported are representative.

No notable difference in RhB diffusivity was found for system composed of PVA/surfactant solutions with the addition of glycerol stock solution (samples $4 \mathrm{f}-4 \mathrm{~h}$, green bars in Fig. 5), in comparison to the ones diluted by water (samples $4 \mathrm{c}-4 \mathrm{e}$, blue bars in Fig. 5). Indeed, experiments performed on the same day resulted in the average diffusion times and distributions of very similar range with no statistically significant difference $(\alpha=0.05)$. It is clear that the addition of glycerol at low concentration does not influence the diffusion coefficient of $\mathrm{RhB}$ in the polymer solutions with the presence of surfactant and therefore that the surfactants are primarily responsible for such a significant change in probe diffusivity. This is consistent with the findings acquired from the PVA/ glycerol binary mixtures (solutions $2 \mathrm{a}-2 \mathrm{e}$, Table 2 ), where addition of glycerol solution has minimal effects on $\mathrm{RhB}$ diffusivity and PVA particle size.

Strong interactions between $\mathrm{RhB}$ and charged surfactants have been identified elsewhere as controlling their behavior both below and above the critical micelle concentration (CMC) due surfactant-dye aggregation or entrapment within micelles [85]. In this study, surfactants were above their respective $\mathrm{CMC}$ for all formulations studied with the exception of samples $4 \mathrm{c}$ and $4 \mathrm{f}$ [86]. The aggregation between $\mathrm{RhB}$ and surfactants (in its zwitterionic form following dissociation) [87] hinders its diffusion rate. The findings presented here agree with a previous study which showed that the diffusion coefficient of RhB was significantly reduced due to the SDS-RhB

Table 3 Viscosity and average hydrodynamic diameter of PVA solutions with the addition of glycerol and surfactant of various head group chemistry

\begin{tabular}{|c|c|c|c|c|c|}
\hline$\overline{\text { Sample }}$ & & Surfactant & $\begin{array}{c}\text { PVA/glycerol/surfactant } \\
\text { molar ratio }\end{array}$ & Average $\eta /(\mathrm{mPa} \cdot \mathrm{s})$ & Average $d_{\mathrm{H}} / \mathrm{nm}$ \\
\hline \multirow[t]{3}{*}{ Addition of water } & $4 \mathrm{c}$ & SDS (-) & $1: 0: 14.5$ & $2.462 \pm 0.200$ & $5.6 \pm 0.2$ \\
\hline & $4 d$ & $\mathrm{C}_{12} \mathrm{E}_{10}(0)$ & $1: 0: 6.7$ & $2.122 \pm 0.034$ & $6.9 \pm 0.1$ \\
\hline & $4 \mathrm{e}$ & CTAB $(+)$ & 1:0:11.4 & $2.877 \pm 0.022$ & $5.1 \pm 0.1$ \\
\hline \multirow[t]{3}{*}{ Addition of glycerol solution } & $4 \mathrm{f}$ & $\operatorname{SDS}(-)$ & $1: 181: 14.5$ & $2.939 \pm 0.043$ & $4.1 \pm 0.1$ \\
\hline & $4 \mathrm{~g}$ & $\mathrm{C}_{12} \mathrm{E}_{10}(0)$ & $1: 181: 6.7$ & $2.313 \pm 0.040$ & $6.0 \pm 0.1$ \\
\hline & $4 \mathrm{~h}$ & CTAB $(+)$ & 1:181:11.4 & $3.060 \pm 0.222$ & $4.5 \pm 0.1$ \\
\hline \multirow{3}{*}{$\begin{array}{l}\text { Addition of } \\
\text { pure glycerol and surfactant }\end{array}$} & $4 \mathrm{i}$ & $\operatorname{SDS}(-)$ & $1: 181: 14.5$ & $5.550 \pm 0.230$ & $2.4 \pm 0.1$ \\
\hline & $4 \mathrm{j}$ & $\mathrm{C}_{12} \mathrm{E}_{10}(0)$ & $1: 181: 6.7$ & $4.315 \pm 0.057$ & $3.9 \pm 0.1$ \\
\hline & $4 \mathrm{k}$ & CTAB $(+)$ & $1: 181: 11.4$ & $5.658 \pm 0.456$ & $2.6 \pm 0.1$ \\
\hline
\end{tabular}




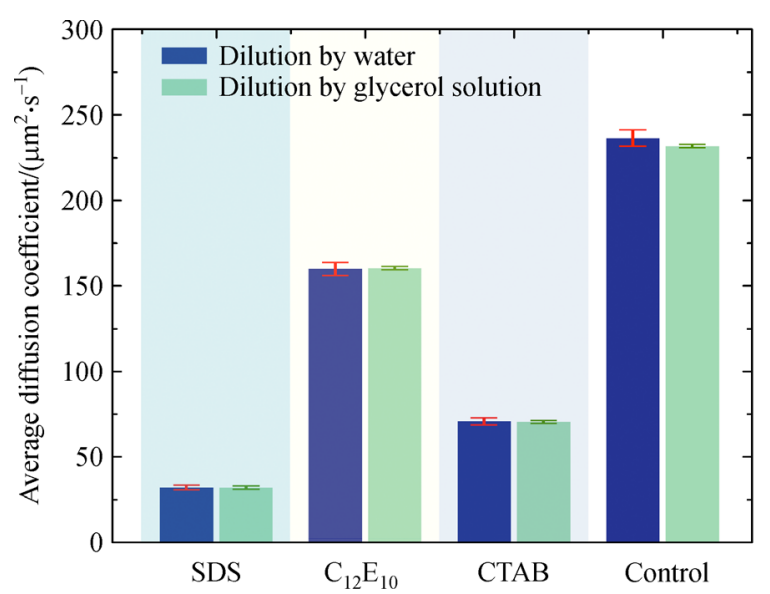

Fig. 5 Average diffusion coefficient of $\mathrm{RhB}$ in PVA solutions with the addition of surfactant and water (samples $4 \mathrm{c}-4 \mathrm{e}$ ) or glycerol solution (samples $4 \mathrm{f}-4 \mathrm{~h}$ ), compared against control samples with no surfactants $(4,4 a)$. Error bars are standard error based on 10 repeats.

interactions that is dependent on the $\mathrm{pH}$ of the solution [88]. In addition, there is a possible polymer-surfactant attraction, whose magnitude is determined by the counterion effect of surfactant on water [89] and the chemical characteristics of the compounds involved [90].

Similarly to SDS, CTAB is likely to form charged aggregates with $\mathrm{RhB}$, leading to a substantial change in the diffusion coefficient of $\mathrm{RhB}$, with a similar magnitude for SDS and CTAB [85]. Even though the number of possible interaction sites for cationic and anionic surfactant is the same, accessibility is probably sterically hindered to the anionic moiety of $\mathrm{RhB}$, which explains the differences of $\mathrm{RhB}$ diffusivity in ternary PVA solutions with cationic and anionic surfactant (Fig. 6).

3.4.1.1 Specific effects of ionic surfactants (SDS and CTAB)

Upon the introduction of charged surfactants, DLS shows a reduction in average $d_{\mathrm{H}}$ of the PVA molecules (Fig. 7, Tables 2 and 3). This effect is consistent in both PVA- surfactant mixtures diluted by water (Fig. 7(a)) and by glycerol (Fig. 7(b)).

The polymer-surfactant interactions via their hydrophobic parts are believed to be a major driving force in the system (Fig. 6) [91,92]. SDS was shown to disrupt polymer aggregates in aqueous solution [31]. Such effect was more pronounced for PVA of low DH (i.e., 70\%) due to an increased fraction of acetate groups in the polymer chains [77]. Moreover, SDS is capable of shifting PVAglycerol interaction to glycerol-SDS interactions in PVA films [83]. Even though presented measurements are in liquid state, those interactions are also plausible. The combined effect of increased molecular crowding due to the presence of surfactant micelles as well as polymersurfactant interactions led to more compact molecular packing, hence decreasing $d_{\mathrm{H}}$ of the PVA.

In addition to the polymer-surfactant interaction, it is likely that the dilution itself could play an important role in the ternary PVA solutions by reducing solution viscosity. In PVA-SDS mixtures, hydrophobic interactions between species result in a preferential adsorption of the surfactants on polymer chains [93], and change viscosity depending on the DH of PVA [92] and amount of surfactant added [93]. Accordingly, both decreased [92,93] and increased [94] viscosity values of PVA solutions containing SDS have been reported. In this study the viscosity decreased, primarily due to the reduced PVA concentration in all solutions discussed in this section after the introduction of surfactant solutions.

Previous studies suggest that CTAB would interact with PVA chain in a similar fashion to SDS, and form a polymer-surfactant complex $[92,94,95]$. Even though the PVA solution was diluted by the surfactant stock solution in the present work, the average $d_{\mathrm{H}}$ of PVA decreased (Tables 2 and 3), while viscosity either increased or remained unchanged compared to samples 4 and $4 \mathrm{a}$ (without addition of surfactant). It is therefore likely that CTAB interacts with PVA via hydrophobic interactions, disrupting the PVA-PVA interactions.

To conclude, two main factors hinder the diffusion of the molecular probe in the PVA-based ternary solutions: first, crowding effect that is caused by the increased polymer (a)

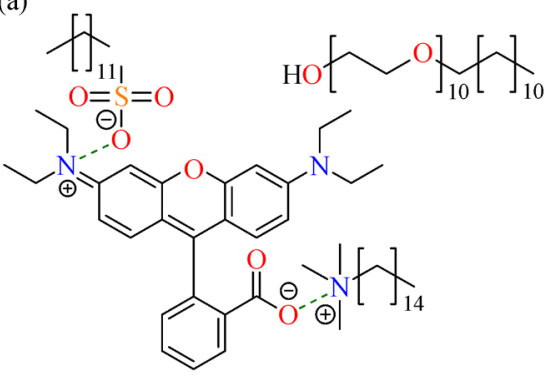

(b)

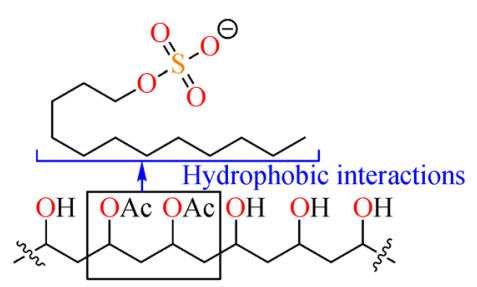

Fig. 6 Possible interactions between (a) RhB and both cationic and anionic surfactants; (b) PVA-surfactant tail group interactions, using SDS molecule as an example. 


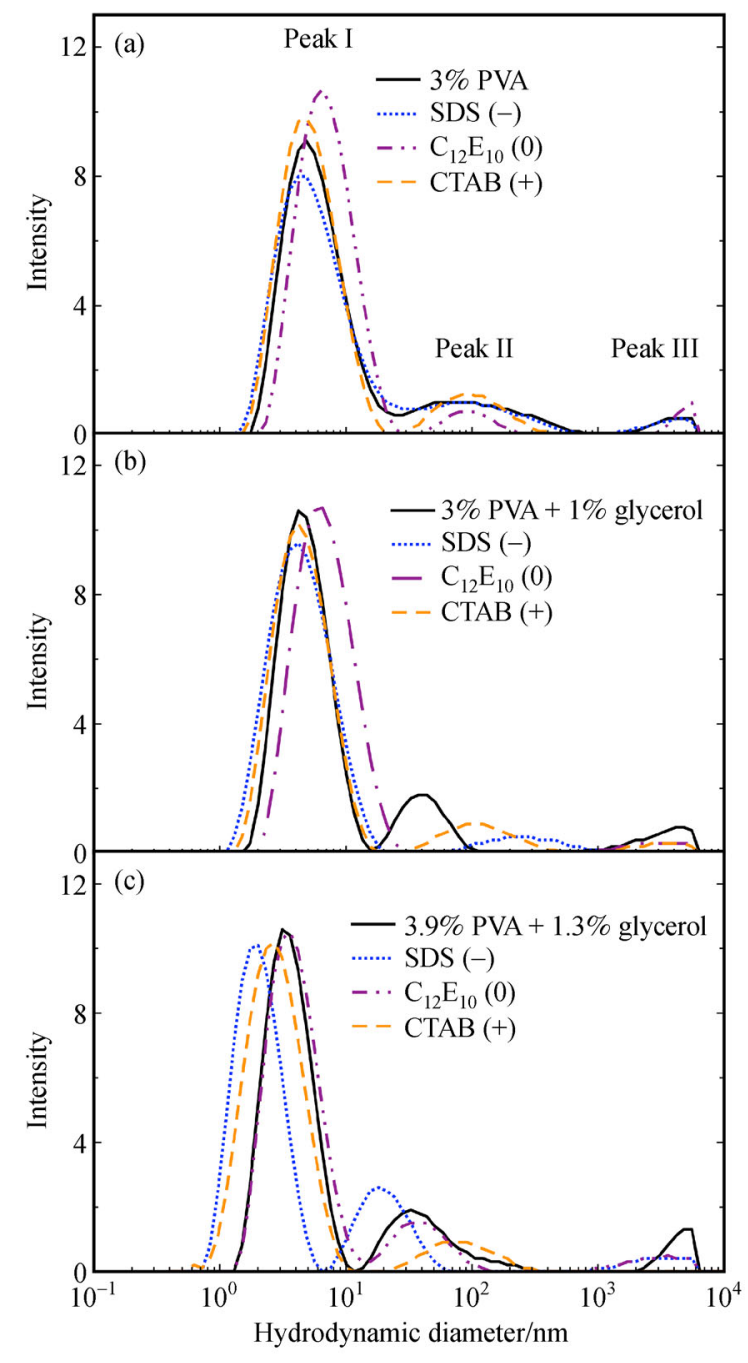

Fig. 7 Particle size distribution for (a) PVA/water/surfactant (compositions 4c-4e), (b) PVA/glycerol/surfactant solutions (compositions $4 \mathrm{f}-4 \mathrm{~h}$ ), and (c) PVA/pure glycerol/pure surfactant solutions (compositions $4 \mathrm{i}-4 \mathrm{k}$ ). The percentages of polymer and glycerol in the graphs are given in $\%(w / v)$.

size and the presence of surfactants; secondly, interactions between $\mathrm{RhB}$ and surfactants that slow down the diffusion of the probe [85] (Fig. 6(a)).

\subsubsection{Effects of nonionic surfactant solutions}

Although adding surfactant solutions resulted in only a slight dilution of PVA-glycerol mixture compared to sample $4 \mathrm{a}$, the presence of nonionic surfactants appeared to have a noticeable effect on the diffusion of the fluorescent probe (Fig. 5). While charge-matching aggregation between $\mathrm{C}_{12} \mathrm{E}_{10}$ and $\mathrm{RhB}$ cannot occur due to its nonionic nature, it remains possible for $\mathrm{C}_{12} \mathrm{E}_{10}$ to interact with PVA via hydrophobic interactions between surfactant tail and acetate groups on the polymer. However, such effect appears to be less pronounced in comparison to CTAB and SDS addition as the ionic strength of the solution remains constant.

Unlike that of SDS and CTAB, stock solution of $\mathrm{C}_{12} \mathrm{E}_{10}$ showed a monomodal size distribution (Fig. S3, cf. ESM), with a $d_{\mathrm{H}}$ very similar to peak I of the PVA particle-size distribution. Indeed, overall $d_{\mathrm{H}}$ of solutions $4 \mathrm{~d}$ and $4 \mathrm{~g}$ increased compared their corresponding surfactant-free solutions (4 and 4a, Tables 1-3). The increased intensity of peak I in sample 4d (Figs. 7(a) and 7(b)) can be related to both individual PVA molecules and micelles of $\mathrm{C}_{12} \mathrm{E}_{10}$. Therefore, the nonionic surfactant acts in a similar way to glycerol in the system, however with a larger effect due to the much larger molecular weight of $\mathrm{C}_{12} \mathrm{E}_{10}$.

Building upon the findings of surfactant-PVA and surfactant $-\mathrm{RhB}$ interactions at low concentrations, systems with the addition of pure glycerol and surfactant to PVA stock solution were investigated to study their influence in the absence of dilution (additional water being introduced) in the system.

\subsubsection{Crowding and binding effects}

Adding pure surfactant and glycerol to PVA solutions showed the same trend to that observed with adding their stock solutions. Their effects on the diffusion of RhB were pronounced in PVA solutions with the addition of anionic surfactant, which decreased by $67 \%$ for composition $4 \mathrm{i}$ compared to composition 4c (90\% compared to $4 \mathrm{~b})$. For cationic and nonionic surfactants, the diffusion coefficients decreased by $44 \%$ and $46 \%$ respectively compared to compositions $4 \mathrm{~d}$ and $4 \mathrm{e}$ (Fig. 8), and by $75 \%$ and $41 \%$, respectively compared to composition $4 \mathrm{~b}$. It is likely that the increased concentration of surfactants led to an additional crowding effect (as seen in the decrease in hydrodynamic diameter in Fig. 7(c)). This is amplified due to the strong interactions between the $\mathrm{RhB}$ and surfactant in the now more concentrated solutions. The variation with different head group chemistry provides further evidence for preferential probe-surfactant interactions for charged surfactants, while the relatively weak response of $\mathrm{C}_{12} \mathrm{E}_{10}$ compared to solution $4 \mathrm{~b}$ again demonstrates its similar behavior to glycerol.

Addition of surfactant to PVA solutions therefore has a significant retarding effect on the diffusivity of $\mathrm{RhB}$, with the driving force for these changes being largely dependent on head group chemistry: 1) For nonionic surfactant $\left(\mathrm{C}_{12} \mathrm{E}_{10}\right)$, a minimal interactions with the fluorescence probe is suspected, with the diffusivity of $\mathrm{RhB}$ being determined by the enhanced crowding effects the surfactant places on the PVA molecules. 2) For anionic surfactant (SDS), there are strong interactions between surfactantPVA and surfactant-probe, leading to a significantly reduced diffusivity compared to the nonionic surfactant. 3) For cationic surfactant (CTAB), although the same type 


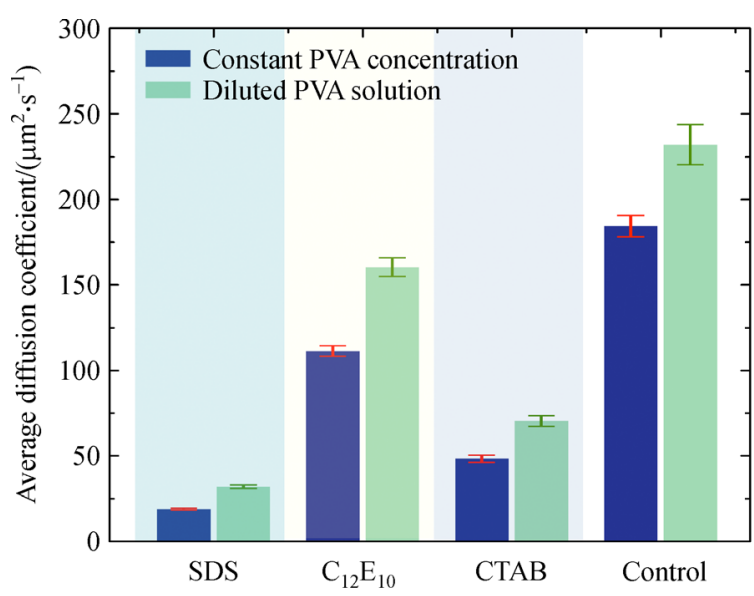

Fig. 8 Average diffusion coefficients of RhB in PVA solutions with the addition of pure glycerol and surfactant (samples $4 \mathrm{i}-4 \mathrm{k}$, blue columns), compared against equivalent samples with the addition of glycerol and surfactant solutions $(4 \mathrm{f}-4 \mathrm{~h}$, green columns) and corresponding control solutions containing no surfactant (4b and 4a). Error bars are standard error based on 10 repeats.

of interactions is present as in the system with SDS (i.e., hydrophobic interactions between tail group and PVA, and charge-matching interactions between head group and $\mathrm{RhB}$ ), steric barriers reducing the surfactant-tracer interaction strength cause a slightly lower change in tracer diffusivity.

The explanations above are supported by the viscosity data presented in Table 3 . The changes in the viscosity of PVA ternary solutions were negligible when nonionic surfactant was used, but significant when ionic surfactants were interacting with the PVA molecules, in agreement with previous findings [94]. For all investigated solutions, no phase separation was observed (which is in line with results published for PVA-water-SDS system) [83].

\section{Conclusions}

Diffusion behaviour of a molecular probe $(\mathrm{RhB})$ in a series of aqueous PVA solutions, representing complex formulations involved in industrial processes, was examined in the present work as a function of polymer and plasticiser concentration, as well as the presence of surfactants of various head group chemistry. For the PVA solutions, our results demonstrate a good agreement with the scaling theory of anomalous diffusion in semi-dilute polymer systems, showing a nonlinear increase of diffusion coefficient of the probe with decreasing polymer concentration. PVA solutions diluted by glycerol solutions do not exhibit significant changes in the mobility of $\mathrm{RhB}$, proving the vital role of PVA concentration. For PVA solutions with an increased glycerol concentration, crowding effects play an important role in the system, leading to a decreased diffusivity of the probe due to the increased diffusion path length.

Crowding effects also provided a plausible explanation for the diffusion kinetics in the PVA solutions with the addition of nonionic surfactant. However, for solutions with the addition of cationic and anionic surfactant, surfactant-PVA and surfactant-RhB interactions play a dominant role, slowing down the migration of the tracer. These interactions are strengthened in the more concentrated PVA solutions with an additional pure glycerol and surfactant (rather than their respective solutions), indicating that the concentration of each individual chemical compound (polymer and additives) present in the PVA ternary solutions has a profound influence on the diffusivity of the molecular probe.

Acknowledgements This research was funded by School of Chemical Engineering, University of Birmingham, and Engineering \& Physical Science Research Council (EPSRC) with grant number EP/P007864/1. ZJZ acknowledges an Industrial Fellowship with $P \& G$, funded by the Royal Academy of Engineering (IF2021\100).

Electronic Supplementary Material Supplementary material is available in the online version of this article at https://dx.doi.org/10.1007/s11705-0212121-3 and is accessible for authorized users.

Open Access This article is licensed under a Creative Commons Attribution 4.0 International License, which permits use, sharing, adaptation, distribution and reproduction in any medium or format, as long as you give appropriate credit to the original author(s) and the source, provide a link to the Creative Commons licence, and indicate if changes were made. The images or other third party material in this article are included in the article's Creative Commons licence, unless indicated otherwise in a credit line to the material. If material is not included in the article's Creative Commons licence and your intended use is not permitted by statutory regulation or exceeds the permitted use, you will need to obtain permission directly from the copyright holder. To view a copy of this licence, visit http://creativecommons.org/licenses/by/4.0/.

\section{References}

1. Moraes I C F, Carvalho R A, Bittante A M Q B, Solorza-Feria J, Sobral P J A. Film forming solutions based on gelatin and poly(vinyl alcohol) blends: thermal and rheological characterizations. Journal of Food Engineering, 2009, 95(4): 588-596

2. Hasimi A, Stavropoulou A, Papadokostaki K G, Sanopoulou M. Transport of water in polyvinyl alcohol films: effect of thermal treatment and chemical crosslinking. European Polymer Journal, 2008, 44(12): 4114-4123

3. Kawai F, Hu X. Biochemistry of microbial polyvinyl alcohol degradation. Applied Microbiology and Biotechnology, 2009, 84(2): 227-237

4. Kim D Y, Rhee Y H. Biodegradation of microbial and synthetic polyesters by fungi. Applied Microbiology and Biotechnology, 2003, 61(4): 300-308

5. Bergo P, Moraes I C F, Sobral P J A. Effects of different moisture contents on physical properties of PVA-gelatin films. Food Biophysics, 2012, 7(4): 354-361

6. El-Nasser H M. Effects of methyl red acidity and UV illumination 
on absorption coefficient of MR/PVA thin films. Physica B, Condensed Matter, 2011, 406(10): 1940-1943

7. Konidari M V, Papadokostaki K G, Sanopoulou M. Moistureinduced effects on the tensile mechanical properties and glasstransition temperature of poly(vinyl alcohol) films. Journal of Applied Polymer Science, 2011, 120(6): 3381-3386

8. Hodge R M, Bastow T J, Edward G H, Simon G P, Hill A J. Free volume and the mechanism of plasticization in water-swollen poly (vinyl alcohol). Macromolecules, 1996, 29(25): 8137-8143

9. Fick A. On liquid diffusion. The London, Edinburgh, and Dublin Hilosophical Magazine and Journal of Science, 1855, 10(63): $30-39$

10. Miller C C. The Stokes-Einstein law for diffusion in solution. Proceedings of the Royal Society of London. Series A, Containing Papers of a Mathematical and Physical Character, 1924, 106(740): 724-749

11. Masuda A, Ushida K, Okamoto T. New fluorescence correlation spectroscopy (FCS) suitable for the observation of anomalous diffusion in polymer solution: time and space dependences of diffusion coefficients. Journal of Photochemistry and Photobiology A Chemistry, 2006, 183(3): 304-308

12. Michelman-Ribeiro A, Horkay F, Nossal R, Boukari H. Probe diffusion in aqueous poly(vinyl alcohol) solutions studied by fluorescence correlation spectroscopy. Biomacromolecules, 2007, 8(5): 1595-1600

13. Bu Z, Russo P S. Diffusion of dextran in aqueous (hydroxypropyl) cellulose. Macromolecules, 1994, 27(5): 1187-1194

14. Amsden B. Solute diffusion in hydrogels: an examination of the retardation effect. Polymer Gels and Networks, 1998, 6(1): 13-43

15. Mustafa M B, Tipton D L, Barkley M D, Russo P S, Blum F D. Dye diffusion in isotropic and liquid crystalline aqueous (hydroxypropyl)cellulose. Macromolecules, 1993, 26(2): 370-378

16. Vrentas J S, Duda J L. Diffusion in polymer-solvent systems. I. Reexamination of the free-volume theory. Journal of Polymer Science. Polymer Physics Edition, 1977, 15(12): 403-416

17. Vrentas J S, Duda J L. Diffusion in polymer-solvent systems. II. A predictive theory for the dependence of diffusion coefficient on temperature, concentration, and molecular weight. Journal of Polymer Science. Polymer Physics Edition, 1977, 15(12): 417-439

18. Phillies G D J. Universal scaling equation for self-diffusion by macromolecules in solution. Macromolecules, 1986, 19(9): 23672376

19. Park I H, Johnson C S, Hill C, Carolina N, Gabriel D A. Probe diffusion in polyacrylamide gels as observed by means of holographic relacation methods: search for a universal equation. Macromolecules, 1990, 23(5): 1548-1553

20. Senanayake K K, Fakhrabadi E A, Liberatore M W, Mukhopadhyay A. Diffusion of nanoparticles in entangled poly(vinyl alcohol) solutions and gels. Macromolecules, 2019, 52(3): 787-795

21. Slim A H, Poling-Skutvik R, Conrad J C. Local confinement controls diffusive nanoparticle dynamics in semidilute polyelectrolyte solutions. Langmuir, 2020, 36(31): 9153-9159

22. Gratz M, Tschöpe A. Size effects in the oscillatory rotation dynamics of $\mathrm{Ni}$ nanorods in poly(ethylene oxide) solutions. Macromolecules, 2019, 52(17): 6600-6612

23. Cherdhirankorn T, Harmandaris V, Juhari A, Voudouris P, Fytas G,
Kremer K, Koynov K. Fluorescence correlation spectroscopy study of molecular probe diffusion in polymer melts. Macromolecules, 2009, 42(13): 4858-4866

24. Senanayake K K, Shokeen N, Fakhrabadi E A, Liberatore M W, Mukhopadhyay A. Diffusion of nanoparticles within a semidilute polyelectrolyte solution. Soft Matter, 2019, 15(38): 7616-7622

25. Wang W, Barkai E, Burov S. Large deviations for continuous time random walks. Entropy (Basel, Switzerland), 2020, 22(6): 697-719

26. Xue C, Shi X, Tian Y, Zheng X, Hu G. Diffusion of nanoparticles with activated hopping in crowded polymer solutions. Nano Letters, 2020, 20(5): 3895-3904

27. Jia D, Muthukumar M. Electrostatically driven topological freezing of polymer diffusion at intermediate confinements. Physical Review Letters, 2021, 126(5): 057802

28. Banks D S, Tressler C, Peters R D, Höfling F, Fradin C. Characterizing anomalous diffusion in crowded polymer solutions and gels over five decades in time with variable-lengthscale fluorescence correlation spectroscopy. Soft Matter, 2016, 12(18): 4190-4203

29. Guillemet F, Piculell L. Interactions in aqueous mixtures of hydrophobically modified polyelectrolyte and oppositely charged surfactant: mixed micelle formation and associative phase separation. Journal of Physical Chemistry, 1995, 99(22): 9201-9209

30. Langevin D. Complexation of oppositely charged polyelectrolytes and surfactants in aqueous solutions: a review. Advances in Colloid and Interface Science, 2009, 147-148: 170-177

31. Lewis K E, Robinson C P. The interaction of sodium dodecyl sulfate with methyl cellulose and polyvinyl alcohol. Journal of Colloid and Interface Science, 1970, 32(3): 539-546

32. Qiu L, Cheng M, Xie A, Shen Y. Study on the viscosity of cationic gemini surfactant-nonionic polymer complex in water. Journal of Colloid and Interface Science, 2004, 278(1): 40-43

33. Negm N A, Mohamed A S, Ahmed S M, El-Raouf M A. Polymercationic surfactant interaction. 1. Surface and physicochemical properties of polyvinyl alcohol (PVA)-S-alkyl isothiouronium bromide surfactant mixed systems. Journal of Surfactants and Detergents, 2015, 18(2): 245-250

34. Trabelsi S, Guillot S, Ritacco H, Boué F, Langevin D. Nanostructures of colloidal complexes formed in oppositely charged polyelectrolyte/surfactant dilute aqueous solutions. European Physical Journal E, 2007, 23(3): 305-311

35. Babak V G, Merkovich E A, Desbrières J, Rinaudo M. Formation of an ordered nanostructure in surfactant-polyelectrolyte complexes formed by interfacial diffusion. Polymer Bulletin, 2000, 45(1): 7781

36. Zana R, Lianos P, Lang J. Fluorescence probe studies of the interactions between poly(oxyethylene) and surfactant micelles and microemulsion droplets in aqueous solutions. Journal of Physical Chemistry, 1985, 89(1): 41-44

37. Wöll D. Fluorescence correlation spectroscopy in polymer science. RSC Advances, 2014, 4(5): 2447-2465

38. Annunziata O, Buzatu D, Albright J G. Protein diffusion coefficients determined by macroscopic-gradient rayleigh interferometry and dynamic light scattering. Langmuir, 2005, 21(26): 12085-12089

39. Ivanov D A, Grossmann T, Winkelmann J. Comparison of ternary diffusion coefficients obtained from dynamic light scattering and 
Taylor dispersion. Fluid Phase Equilibria, 2005, 228-229: 283-291

40. Wang S, Sun P, Zhang R, Lu A, Liu M, Zhang L. Cation/ macromolecule interaction in alkaline cellulose solution characterized with pulsed field-gradient spin-echo NMR spectroscopy. Physical Chemistry Chemical Physics, 2017, 19(11): 7486-7490

41. Baldwin R L, Ogston A G. The diffusion and sedimentation coefficients of a liquid two-component system in terms of macroscopic properties of the system. Transactions of the Faraday Society, 1954, 50: 749-755

42. Ono M, Mashim T. Sedimentation process for atoms in a Bi-Sb system alloy under a strong gravitational field: a new type of diffusion of substitutional solutes. Philosophical Magazine. A. Physics of Condensed Matter. Structure, Defects and Mechanical Properties, 2002, 82(3): 591-600

43. Zettl U, Hoffmann S T, Koberling F, Krausch G, Enderlein J, Harnau L, Ballauff M. Self-diffusion and cooperative diffusion in semidilute polymer solutions as measured by fluorescence correlation spectroscopy. Macromolecules, 2009, 42(24): 9537-9547

44. Giacin J R. Evaluation of plastics packaging materials for food packaging applications: food safety considerations. Journal of Food Safety, 1980, 2(4): 257-276

45. Liu R, Gao X, Adams J, Oppermann W. A fluorescence correlation spectroscopy study on the self-diffusion of polystyrene chains in dilute and semidilute solution. Macromolecules, 2005, 38(21): 8845-8849

46. Zettl H, Zettl U, Krausch G, Enderlein J, Ballauff M. Direct observation of single molecule mobility in semidilute polymer solutions. Physical Review. E, 2007, 75(6): 194-196

47. Zettl H, Hafner W, Boker A, Schmalz H, Lanzendorfer M, Muller A H E, Krausch G. Fluorescence correlation spectroscopy of single dye-labeled polymers in organic solvents. Macromolecules, 2004, 37(5): 1917-1920

48. Cai L, Panyukov S, Rubinstein M. Mobility of nonsticky nanoparticles in polymer liquids. Macromolecules, 2011, 44(19): 7853-7863

49. Cherdhirankorn T, Best A, Koynov K, Peneva K, Muellen K, Fytas G. Diffusion in polymer solutions studied by fluorescence correlation spectroscopy. Journal of Physical Chemistry B, 2009, 113(11): 3355-3359

50. Boukari H, Nossal R, Sackett D, Schuck P. Hydrodynamics of nanoscopic tubulin rings in dilute solutions. Physical Review Letters, 2004, 93(9): 098106

51. Michelman-Ribeiro A, Boukari H, Nossal R, Horkay F. Fluorescence correlation spectroscopy study of probe diffusion in poly (vinyl alcohol) solutions and gels. Macromolecular Symposia, 2005, 227(1): 221-230

52. Pristinski D, Kozlovskaya V, Sukhishvili S A. Fluorescence correlation spectroscopy studies of diffusion of a weak polyelectrolyte in aqueous solutions. Journal of Chemical Physics, 2005, 122(1): 14907-14910

53. Zhao J J, Bae S C, Xie F, Granick S. Diffusion of polymer-coated nanoparticles studied by fluorescence correlation spectroscopy. Macromolecules, 2001, 34(10): 3123-3126

54. Enderlein J, Gregor I, Patra D, Dertinger T, Kaupp U B. Performance of fluorescence correlation spectroscopy for measuring diffusion and concentration. ChemPhysChem, 2005, 6(11): 2324-
2336

55. Zustiak S P, Nossal R, Sackett D L. Hindered diffusion in polymeric solutions studied by fluorescence correlation spectroscopy. Biophysical Journal, 2011, 101(1): 255-264

56. Rusu L, Lumma D, Rädler J O. Charge and size dependence of liposome diffusion in semidilute biopolymer solutions. Macromolecular Bioscience, 2010, 10(12): 1465-1472

57. Vagias A, Raccis R, Koynov K, Jonas U, Butt H, Fytas G, Kosovan P, Lenz O, Holm C. Complex tracer diffusion dynamics in polymer solutions. Physical Review Letters, 2013, 111(8): 088301

58. Omari R A, Aneese A M, Grabowski C A, Mukhopadhyay A. Diffusion of nanoparticles in semidilute and entangled polymer solutions. Journal of Physical Chemistry B, 2009, 113(25): 84498452

59. Rashid R, Chee S M L, Raghunath M, Wohland T. Macromolecular crowding gives rise to microviscosity, anomalous diffusion and accelerated actin polymerization. Physical Biology, 2015, 12(3): 034001

60. Ochab-Marcinek A, Hołyst R. Scale-dependent diffusion of spheres in solutions of flexible and rigid polymers: mean square displacement and autocorrelation function for FCS and DLS measurements. Soft Matter, 2011, 7(16): 7366-7369

61. Dong Y, Feng X, Zhao N, Hou Z. Diffusion of nanoparticles in semidilute polymer solutions: a mode-coupling theory study. Journal of Chemical Physics, 2015, 143(2): 024903

62. Mchedlov-Petrossyan N O, Vodolazkaya N A, Doroshenko A O. Ionic equilibria of fluorophores in organized solutions: the Influence of micellar microenvironment on protolytic and photophysical properties of rhodamine B. Journal of Fluorescence, 2003, 13(3): 235-248

63. Merouani S, Hamdaoui O, Saoudi F, Chiha M. Sonochemical degradation of rhodamine $\mathrm{B}$ in aqueous phase: effects of additives. Chemical Engineering Journal, 2010, 158(3): 550-557

64. Arbeloa I L, Ojeda P R. Molecular forms of rhodamine B. Chemical Physics Letters, 1981, 79(2): 347-350

65. Soares E T, Lansarin M A, Moro C C. A study of process variables for the photocatalytic degradation of rhodamine B. Brazilian Journal of Chemical Engineering, 2007, 24(1): 29-36

66. Goins A B, Sanabria H, Waxham M N. Macromolecular crowding and size effects on probe microviscosity. Biophysical Journal, 2008, 95(11): 5362-5373

67. Mohsin M, Hossin A, Haik Y. Thermal and mechanical properties of poly(vinyl alcohol) plasticized with glycerol. Journal of Applied Polymer Science, 2011, 122(5): 3102-3109

68. Dix L R, Gilblas R. Lyotropic and interfacial behaviour of an anionic gemini surfactant. Journal of Colloid and Interface Science, 2006, 296(2): 762-765

69. Zhang Z, Mosey M, Alswieleh A, Morse A J, Lewis A L, Geoghegan M, Leggett A J. Effect of salt on phosphorylcholinebased zwitterionic polymer brushes. Langmuir, 2016, 32(20): 50485057

70. Shakouri A, Ahmari H, Hojjat M, Zeinali Heris S. Effect of $\mathrm{TiO}_{2}$ nanoparticle on rheological behavior of poly(vinyl alcohol) solution. Journal of Vinyl and Additive Technology, 2017, 23(3): 234-240

71. Stetefeld J, McKenna S A, Patel T R. Dynamic light scattering: a practical guide and applications in biomedical sciences. Biophysical 
Reviews, 2016, 8(4): 409-427

72. Phillies G D J. Dynamics of macromolecules in concentrated solutions: the universal scaling function derived. Macromolecules, 1987, 20(3): 558-564

73. Briddick A, Li P, Hughes A, Courchay F, Martinez A, Thompson R L. Surfactant and plasticizer segregation in thin poly(vinyl alcohol) films. Langmuir, 2016, 32(3): 864-872

74. Korosi A, Fabuss B M. Viscosity of liquid water from 25 to $150{ }^{\circ} \mathrm{C}$ : measurements in pressurized glass capillary viscometer. Analytical Chemistry, 1968, 40(1): 157-162

75. Sozański K, Wiśniewska A, Kalwarczyk T, Hołyst R. Activation energy for mobility of dyes and proteins in polymer solutions: from diffusion of single particles to macroscale flow. Physical Review Letters, 2013, 111(22): 228301

76. Ohta T, Nakanishi A. Theory of semi-dilute polymer solutions. I. Static property in a good solvent. Journal of Physics. A, Mathematical and General, 1983, 16(17): 4155-4170

77. Atanase L I, Riess G. Poly(vinyl alcohol-co-vinyl acetate) complex formation with anionic surfactants particle size of nanogels and their disaggregation with sodium dodecyl sulfate. Colloids and Surfaces. A, Physicochemical and Engineering Aspects, 2010, 355(1-3): 2936

78. Kjøniksen A L, Nyström B. Dynamic light scattering of poly(vinyl alcohol) solutions and their dynamical behavior during the chemical gelation process. Macromolecules, 1996, 29(22): 7116-7123

79. Taylor S J, Haw M D, Sefcik J, Fletcher A J. Gelation mechanism of resorcinol-formaldehyde gels investigated by dynamic light scattering. Langmuir, 2014, 30(34): 10231-10240

80. Tomaszewska E, Soliwoda K, Kadziola K, Tkacz-Szczesna B, Celichowski G, Cichomski M, Szmaja W, Grobelny J. Detection limits of DLS and UV-Vis spectroscopy in characterization of polydisperse nanoparticles colloids. Journal of Nanomaterials, 2013, 2013: 1-10

81. Kok C M, Rudin A. Relationship between the hydrodynamic radius and the radius of gyration of a polymer in solution. Die Makromolekulare Chemie. Rapid Communications, 1981, 2(11): 655-659

82. Hong $\mathrm{P}, \mathrm{Chou} \mathrm{C}, \mathrm{He} \mathrm{C}$. Solvent effects on aggregation behavior of polyvinyl alcohol solutions. Polymer, 2001, 42(14): 6105-6112

83. Briddick A, Fong R J, Sabattie E F D, Li P, Skoda M W A, Courchay F, Thompson R L. Blooming of smectic surfactant/ plasticizer layers on spin-cast poly(vinyl alcohol) films. Langmuir, 2018, 34(4): 1410-1418

84. Sheely M L. Glycerol viscosity tables. Industrial \& Engineering Chemistry, 1932, 24(9): 1060-1064

85. Tajalli H, Ghanadzadeh Gilani A, Zakerhamidi M S, Moghadam M. Effects of surfactants on the molecular aggregation of rhodamine dyes in aqueous solutions. Spectrochimica Acta. Part A: Molecular and Biomolecular Spectroscopy, 2009, 72(4): 697-702

86. Hansson P, Lindman B. Surfactant-polymer interactions. Current Opinion in Colloid \& Interface Science, 1996, 1(5): 604-613

87. McHedlov-Petrosyan N O, Kholin Y V. Aggregation of rhodamine B in water. Russian Journal of Applied Chemistry, 2004, 77(3): 414-422

88. Haglund B O, Sundelöf L, Upadrashta S M, Wurster D E. Effect of SDS micelles on rhodamine-B diffusion in hydrogels. Journal of Chemical Education, 1996, 73(9): 889

89. Saito S, Yukawa M. Interactions of polymers and cationic surfactants with thiocyanate as counterions. Journal of Colloid and Interface Science, 1969, 30(2): 211-218

90. Saito S, Kitamura K. Counterion effect of tetraalkylammonium and long-chain alkylammonium salts in the interaction with nonionic polymers. Journal of Colloid and Interface Science, 1971, 35(2): 346-353

91. Nakagaki M, Ninomiya Y. Colloid chemical studies of starching materials. VI. Viscometric studies of the interaction between polyvinyl alcohol and sodium dodecyl sulfate. Bulletin of the Chemical Society of Japan, 1964, 37(6): 817-821

92. Arai $\mathrm{H}$, Horin $\mathrm{S}$, Goods $\mathrm{H}$. Interaction between polymer and detergent in aqueous solution. Journal of Colloid and Interface Science, 1969, 30(3): 372-377

93. Isemura $\mathrm{T}$, Imanishi A. The dissolution of water-insoluble polymers in the surfactant solution: the polyelectrolyte-like behavior of the dissolved polymers. Journal of Polymer Science, 1958, 33(126): 337-352

94. Jia L, Qin X. The effect of different surfactants on the electrospinning poly(vinyl alcohol) (PVA) nanofibers. Journal of Thermal Analysis and Calorimetry, 2013, 112(2): 595-605

95. Tadros T F. The interaction of cetyltrimethylammonium bromide and sodium dodecylbenzene sulfonate with polyvinyl alcohol: adsorption of the polymer-surfactant complexes on silica. Journal of Colloid and Interface Science, 1974, 46(3): 528-540 